\title{
Psychological Aspects of Care of the Critically Ill Child
}

\author{
Gillian A. Colville ${ }^{1}$ \\ 1 Paediatric Psychology Service, St George's Hospital, London, \\ United Kingdom \\ J Pediatr Intensive Care 2015;4:182-187.
}

\begin{abstract}
Address for correspondence Gillian A. Colville, BSc, MPhil, Paediatric Psychology Service, 2nd Floor Clare House, St George's Hospital, Blackshaw Road SW17 0QT, London, United Kingdom (e-mail: gcolvill@sgul.ac.uk).
\end{abstract}

\author{
Abstract \\ Keywords \\ - pediatric intensive \\ care \\ - posttraumatic stress \\ - delirium \\ - outcomes \\ - quality of life
}

Recent improvements in mortality rates in pediatric intensive care have led to an increasing focus on the physical and psychological morbidity of pediatric patients. In this review, guidance on the acute psychological management of children, during and shortly after their intensive care treatment, is provided. This is informed by the current state of knowledge regarding the nature of children's experiences of intensive care and the expanding literature on their subsequent psychological symptoms. The relevance to pediatric settings of the current debate about the significance of delirium, and other recent research and guidance regarding the management of psychological issues in adult intensive care settings, is considered. The importance of distinguishing between children's self-report and parents' proxy report is also discussed in relation to establishing the causes of the child's distress in this situation and suggestions are made of ways to help children better understand what has happened to them.

\section{Introduction}

The history of pediatric intensive care over the past 40 years has been one of enormous successes in relation to mortality rates. The number of conditions we can now treat has increased and it is clear that many children are alive now who would not have been before. This has shifted the focus of the intensive care community to the importance of examining morbidity outcomes, and to wrestle with the issue of determining quality of life in survivors. ${ }^{1}$ A recent large prospective study has raised the possibility that we may have exchanged morbidity for mortality and there have been calls for units to increase efforts to follow up their patients after discharge to gather more information on their longer-term outcomes. ${ }^{2,3}$ There has also been a concurrent increase in interest in patients' psychological morbidity, with a growing number of studies asking older children directly about what they remember about their admission to pediatric intensive care unit (PICU) and how they feel after the admission. ${ }^{4-7}$ So, it is that we are gradually coming to a more comprehensive understanding

received

December 5, 2014 accepted after revision December 10, 2014 published online August 26, 2015
Issue Theme Physical Therapy and Rehabilitation in Pediatric Critical Care; Guest Editor: Karen Choong, MB, BCh, FRCP(C), MSC of what critical care means to a child, over and above the difference between life and death.

In this article, I will attempt to summarize the current state of knowledge on the psychological aspects of the care of the critically ill child in the hospital setting. This will involve addressing their experiences acutely as they gradually adjust to what has happened to them and will be informed by the literature on what they remember and what most troubles them in the months following discharge. Although I will not address the impact on parents in detail here, it is important to acknowledge that this is a very important consideration in the management of critically ill children because of the particular level of dependence they have on their parents both for their day-to-day care and their general emotional well-being. Indeed in relation to this, a recent editorial has argued that we have a moral obligation to our patients to support the people caring for them. ${ }^{8}$ In the context of the child's acute care on the PICU although for obvious reasons the main focus of care will be primarily medical, it should ideally be informed by an understanding of child development and of the primacy of the family in the child's life. Apart from the general issues,
Copyright $\odot 2015$ by Georg Thieme Verlag KG, Stuttgart · New York
DOI http://dx.doi.org/ 10.1055/s-0035-1563542. ISSN 2146-4618. 
which arise whenever a child is admitted to hospital, there are special considerations relating to critical care. These include the problem of delirium, about which there is a burgeoning adult literature and the gap in the patient's understanding, also well documented in adult intensive care patients, that often arises because of the incomplete memory they have of events when they are particularly unwell, either because they are unconscious or heavily sedated. ${ }^{9}$ There is also clearly an increased risk in relation to an admission to PICU that children (and family) are exposed to a range of traumatic experiences-both directly in relation to what happens to the child and indirectly in terms of what they witness.

\section{Pediatric Delirium}

\section{Relevant Adult Research}

In the past decade, there has been a growing appreciation of the prevalence of delirium in adult intensive care patients since the publication of seminal articles by Ely and his colleagues $^{10-12}$ demonstrating an association between delirium and increased length of stay, mortality, and morbidity. Further studies have shown that the use of interrupted sedation has led to lower rates of delirium, with concomitant reductions in length of stay and associated medical and psychological problems, and have informed recent guidelines on the management of pain, agitation, and delirium in adult intensive care settings. ${ }^{13-15}$

Recent adult studies have, however, provided more finegrained analyses of these associations and have begun to question the status of delirium as necessarily indicative of the risk of poorer long-term outcome, although it is often associated with it. In particular, Klein Klouwenberg et al $^{16}$ in a study of more than 1,000 patients have demonstrated no increased risk of mortality for delirium despite the associated increased length of stay, once severity of illness is controlled for in multivariate analyses. Also, the original indications that delirium might be associated with a higher risk of psychological sequelae have not been replicated in larger longitudinal cohort studies, although there is evidence that the presence of memories of the delusional experiences that can occur when a patient is delirious do increase risk of posttraumatic stress symptoms. ${ }^{17,18}$ Another important recent study in this field has uncovered evidence that the current tool-based approach to measuring delirium in adult intensive care settings may be overidentifying a rapidly resolving form of delirium, which seems to be clearly linked to level of sedation. ${ }^{19}$

\section{Pediatric Research}

Currently, the evidence base for risks associated with delirium in pediatric intensive care patients is much smaller, although there is a growing acknowledgment of its importance and evidence of a link with increased length of stay. ${ }^{20,21}$ There is also evidence, from a longitudinal study of 102 PICU survivors, that the presence of delusional memories, which was associated with length of sedation, was also independently associated with posttraumatic stress symptoms 3 months after discharge, even when controlling for severity of illness. $^{22}$ Interestingly, in this study, the protective effect of factual memory for events described in adult ICU survivors ${ }^{23}$ was not found. It may therefore be the case that children are more troubled by their delusional experiences than adultspossibly because of their lack of life experience. Although adult patients might be able to work out that some of the more bizarre things ${ }^{24}$ they remember happening on ICU could not possibly have happened, a child may remain less convinced.

The true prevalence of delirium on PICU is unknown because of the limitations of the tools that have been available until recently and the consequent current lack of routine assessment, but it is a condition regularly diagnosed by psychiatrists where they are consulted by pediatric intensivists and is clearly a feature of children's experience in intensive care. A review of psychiatric referrals at one center has suggested that there is a preponderance of hyperactive delirium in pediatric intensive care patients but acknowledges that this may be because the hypoactive cases are, by definition, less likely to be noticed and are consequently diagnosed less often or wrongly assumed to be evidence of low mood or fatigue. ${ }^{25,26}$ Once we have a consensus on how best to assess delirium we will be in a better position to see if the associated risk factors are the same as those documented in adults. We will also be able to compare treatments for it and to evaluate preventive strategies designed to minimize it.

\section{Assessment of Delirium}

A major stumbling block in this field has been the lack of standardized assessment tools that can measure delirium in children across the age range-and in particular in very young or otherwise nonverbal children who, in practice, make up the majority of admissions to PICU. Smith et $\mathrm{al}^{27}$ have adapted a well-validated adult delirium measure (the confusion assessment method) for use with children aged 5 years and above, producing a modified version known as the pediatric confusion assessment method for the ICU. It is available in several languages and has been shown to have good psychometric properties and validity when compared with a formal psychiatric diagnostic assessment.

Three other groups of researchers, two in Europe and one in the United States of America, have come up with alternative tools, which are more applicable for use with younger children and infants. Janssen et $\mathrm{al}^{28}$ have shown that the pediatric anesthesia emergence delirium scale is more useful than other delirium scales with this population and have suggested ways of supplementing it to facilitate diagnosis in the youngest patients by adding additional questions for the parent about how the child's presentation compares with its usual behavior and considering that refractory agitation might be a marker of delirium in infants. ${ }^{29,30}$ Another European team has suggested that an existing scale which measures withdrawal symptoms in children (the Sophia observation withdrawal symptoms scale) might also have utility in terms of identifying pediatric patients with delirium. ${ }^{31}$

Most recently, a new scale, the Cornell assessment of pediatric delirium, ${ }^{32}$ has been validated for use on PICU. It 
includes useful reference information on normal behavior in infants of different ages for comparison purposes, takes only a couple of minutes to complete, and has been validated against the gold standard, that is, psychiatric assessment, for use across the age range on PICU, although the authors report lower specificity with children with developmental delay.

\section{Management of Delirium}

There are a small number of studies reporting on the apparent effectiveness of certain medications for delirium in small case series of children, ${ }^{30,33}$ but with the current gaps in our understanding of the natural history of this condition in children in this situation, and the fact that by definition delirium is a fluctuating condition which is self-limiting, these should be regarded with some caution.

It is also worth considering the potential role of nonpharmacological interventions, such as strategies to increase the patient's orientation to their surroundings-like providing favorite toys or blankets, a clock or a window view, and, for longer-term patients, a daily activity plan on the wall. These have been found helpful with elderly patients who often become delirious or confused when unwell and have reduced their requirements for sedation. ${ }^{34}$ Parental presence-their touch and the sound of their familiar voices-can clearly be invaluable here and if the child has been away from home for a long time, a brief visit from another important family member, friend, or teacher can often lift their morale and remind them who they are, as well as reassuring them that people are thinking of them. A visit from a pet, where this is possible, can also lift a child's mood where other strategies have failed. ${ }^{35}$

It is important also to be mindful of the psychological impact of delirium on families and children and, at the very least, provide psychoeducation for families about the possibility that a child might react in this way. In relation to this, it should be noted that as the majority of children spend only a few days in intensive care, the most striking symptoms of delirium in these children may only become apparent after they have been transferred to the floor, so it is important also to make our nursing and physician colleagues on the general wards more aware of these phenomena, which can give rise to considerable distress for the child both acutely and in retrospect, in the form of troubling memories. It is clear from discussions with families that they find delirium very distressing to watch in their child, particularly if they have not been fore-warned about the possibility that this could happen or if there is any fear that the child may have sustained brain damage which could affect their behavior or their ability to recognize the people closest to them. Just as adult intensive care patients can sometimes report the delusional belief that their relatives have been replaced by impostors, ${ }^{36}$ so too children have been known to report fearing that their parents had been replaced by aliens when they first awoke in a delirious state on the unit. ${ }^{22}$

\section{Case Example of Behavioral Management of Delirium} Johnny, 11 years old, who was in PICU for a month following a road accident in which he suffered serious internal injuries and fractured his pelvis, appeared very fearful in the days following extubation and was therefore referred to the unit psychologist. He confided that there were monsters under his bed but that he was too scared to ask the staff to make them go away. It was explained to his mother that this was likely to be delirium. She found that she was unable to reassure her son, but that he became calmer when she stopped challenging him and agreed to sweep the monsters away each morning when she came in. The symptoms gradually lessened and in time, the child was able to understand that the monsters had not been real and even to see the funny side of it.

\section{Psychological Adjustment}

\section{Memory and Understanding}

There are risks both of overestimating and underestimating what the child remembers, but from the research data available, it seems most children's memories of PICU are neutral $^{22,37}$ and a significant minority of children do not remember anything about their admission at all, which is a comfort to some but bewildering to others.

Children, once they are well and alert enough to interact, often appreciate an explanation of any unusual delusional symptoms they may have experienced when delirious. They are, however, unlikely to voluntarily bring up the matter as there is often a paranoid flavor to the content of their delusional memories which makes them unsure whether it is safe to discuss them-and in some cases they may be afraid they are going mad.

Although parents find the sight of their child on the ventilator traumatic, only a minority of children remember any sensation of the presence of the endotracheal tube, ${ }^{22}$ but it can be useful to make them aware that they were intubated if they are later bewildered to find they have a sore throat or a hoarse voice. It should be borne in mind, however, that they may well be frightened by pain and debilitated by fatigue and therefore only be able to handle brief age-appropriate explanations initially, which may need to be repeated several times. Health professionals and family members need to bear in mind that anxiety, fatigue, and the need to muster such resources as they can to cope with the ongoing ordeal of further treatment will limit their ability to take in new information.

Where units have access to input from child life specialists or pediatric psychologists, it can be helpful to make a storybook for a child who has had a particularly traumatic stay and is struggling to understand what has happened ${ }^{38}$ and some children may find it helpful to draw what they remember ( - Fig. 1). For older children, or where less time is available for preparation, as in the situation where a patient is soon to be discharged, a personalized calendar can serve a similar purpose by informing and orientating the patient to what has happened to them. In such a document, it is possible to illustrate how long the child was unconscious and to provide the dates of key procedures for future reference, interspersed with other important dates in the child's life, which may have passed unnoticed if they were ventilated at the time.

There are challenges, however, inherent in deciding how to present what may be quite complex information about the 

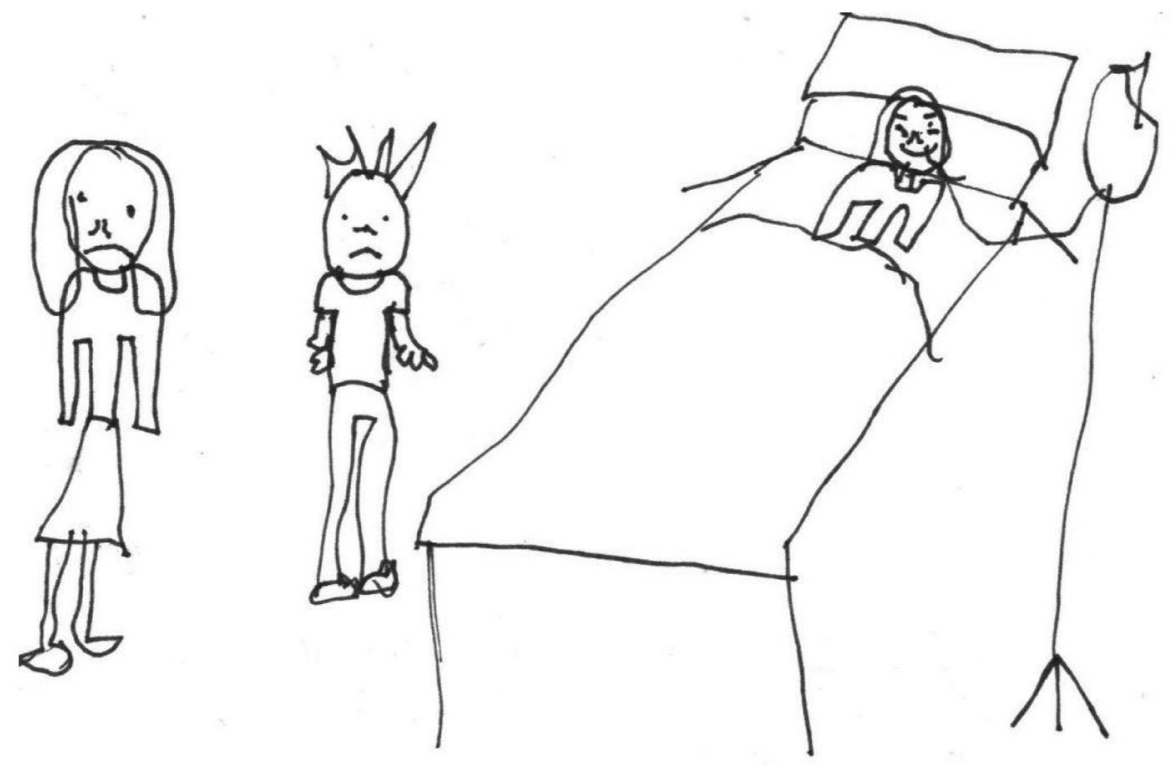

Fig. 1 A drawing by a 9-year-old child who spent 3 weeks on pediatric intensive care unit with a respiratory infection.

child's medical condition and treatment in a developmentally appropriate way, such that this is informative without being overly alarming.

\section{Distress}

In the short term, the priorities in terms of psychologically informed support for children after PICU treatment are to encourage them to engage with the world again; to trust the people who are trying to help them, but who they may now associate with hurting them; to regain some kind of routine; to find appropriate forms of distraction in the form of play activities; to adjust to the changes in their physical condition, which may include some degree of disfigurement; and to contend with their ongoing treatment. In helping them negotiate all of the above, parents may also appreciate guidance on how best to strike a balance between making allowance for what has happened and resisting the temptation to become overprotective, which they readily acknowledge in themselves in research interviews. ${ }^{39}$

In addition to delirium, and the disturbing delusional experiences this may entail, there are many other experiences the child will have to contend with before their discharge from hospital, which have the potential to disturb their psychological equilibrium. They are also likely, especially if they have very little recollection of events leading up to or during their initial admission, to be upset by the changes to their body if they are disfigured or have lost a significant amount of weight. It will also be disturbing for children to wake up to find themselves attached to numerous lines and machines which restrict their ability to move.

However, although the context of critical care is one of life threat, it is important to recognize that the things that cause the child to become particularly distressed are not always those most obviously linked to their medical status. A child may understandably be terrified to wake up for the first time in PICU in the night, to find they are in a strange place with no memory of what has brought them there and no sign of their parents at their bedside to comfort them. ${ }^{40}$ Older children sometimes report being upset and embarrassed when they realize they are in a diaper and they may be much more upset about having an injection or suddenly vomiting. In this respect, they resemble a group of children who in the course of being interviewed about their fears about magnetic resonance imaging reported greater anxiety about the prospect of the blood test scheduled beforehand. ${ }^{41}$ There is evidence from interviews with child-parent pairs in the year following PICU discharge, which shows that parents are troubled by different aspects of the experience than their children and consequently risk misjudging the causes of their child's distress in the recovery period. ${ }^{40}$ More generally in pediatric settings, there is research evidence that it is better to ascertain a child's concerns directly if possible. Parents are not as accurate at estimating their child's emotional quality of life as they are at judging physical quality of life. ${ }^{42}$ Also, their perception of the degree to which their child is suffering posttraumatic stress symptoms is heavily influenced by the presence of these symptoms in themselves-both in terms of the risk of overestimating and underestimating the child's distress. ${ }^{43}$

Another consideration in relation particularly to the acute period where a child is still in PICU or the step-down highdependency area is the issue of what the child may have witnessed. It is sometimes the case that the less sick child, who is more aware of their surroundings, might be more traumatized than another child who is objectively more unwell and unconscious throughout admission with no recollection of it at all. Noyes ${ }^{44}$ has reflected thoughtfully on this issue in relation to long-term ventilated children who may spend many weeks fully alert in an acute setting, while they await discharge, referring to evidence that they can witness a high number of resuscitations and other distressing 
procedures being administered to their fellow patients. ${ }^{45}$ Sometimes, the child's ability to adjust to what has happened will be delayed for some time while the main priorities are driven by a more biological than psychological agenda. After a long or particularly traumatic admission, they may need to be motivated to eat and to mobilize. In practice, they may also need to regain physical strength before they can begin to address recovery on a psychological level and indeed may only report significant levels of symptoms many months later. $^{40,46}$

\section{Conclusion}

In conclusion, there is still clearly much for us to learn in this field. In particular, we need to agree to a more consistent way to diagnose and manage delirium ${ }^{47}$ and we still understand very little about the long-term neurocognitive impact of critical illness which is increasingly being recognized in adult intensive care survivors, although there is some preliminary evidence which suggests elevated risks, particularly in pediatric patients with sepsis treated in PICU. ${ }^{48-50}$ We also need more longitudinal studies asking children directly about their experiences of PICU, but it is encouraging that information is emerging on their self-reported quality of life $\mathrm{e}^{51}$ and a new multicenter study, following PICU families for 3 years, is currently underway. ${ }^{52}$

Finally, although it is incumbent on us to recognize the ongoing difficulties of our patients and do as much as we can to improve the quality of care of children and families in this traumatic situation, we should not forget the many stories of successful adaptation that are also a regular feature of this work. We would do well to remember and respect the power of human resilience and the many examples of this "ordinary magic" we are privileged to witness every day. ${ }^{53}$

\section{References}

1 Namachivayam P, Shann F, Shekerdemian L, et al. Three decades of pediatric intensive care: who was admitted, what happened in intensive care, and what happened afterward. Pediatr Crit Care Med 2010;11(5):549-555

2 Pollack MM, Holubkov R, Funai T, et al; Eunice Kennedy Shriver National Institute of Child Health and Human Development Collaborative Pediatric Critical Care Research Network. Pediatric intensive care outcomes: development of new morbidities during pediatric critical care. Pediatr Crit Care Med 2014;15(9):821-827

3 Morrison W. Mortality, morbidity, and pediatric critical care. Pediatr Crit Care Med 2010;11(5):630-631

4 Colville $\mathrm{G}$. The psychologic impact on children of admission to intensive care. Pediatr Clin North Am 2008;55(3):605-616, x

5 Davydow DS, Richardson LP, Zatzick DF, Katon WJ. Psychiatric morbidity in pediatric critical illness survivors: a comprehensive review of the literature. Arch Pediatr Adolesc Med 2010;164(4):377-385

6 Nelson LP, Gold JI. Posttraumatic stress disorder in children and their parents following admission to the pediatric intensive care unit: a review. Pediatr Crit Care Med 2012;13(3):338-347

7 Rennick JE, Rashotte J. Psychological outcomes in children following pediatric intensive care unit hospitalization: a systematic review of the research. J Child Health Care 2009;13(2):128-149

8 Hoehn KS. Posttraumatic stress and technology: do extracorporeal membrane oxygenation programs have an ethical obligation to provide ongoing psychological support for parents?* Pediatr Crit Care Med 2014;15(2):180-181

9 Griffiths RD, Jones C. Filling the intensive care memory gap? Intensive Care Med 2001;27(2):344-346

10 Ely EW, Shintani A, Truman B, et al. Delirium as a predictor of mortality in mechanically ventilated patients in the intensive care unit. JAMA 2004;291(14):1753-1762

11 Ely EW, Gautam S, Margolin R, et al. The impact of delirium in the intensive care unit on hospital length of stay. Intensive Care Med 2001;27(12):1892-1900

12 Morandi A, Rogers BP, Gunther ML, et al; VISIONS Investigation, VISualizing Icu SurvivOrs Neuroradiological Sequelae. The relationship between delirium duration, white matter integrity, and cognitive impairment in intensive care unit survivors as determined by diffusion tensor imaging: the VISIONS prospective cohort magnetic resonance imaging study. Crit Care Med 2012; 40(7):2182-2189

13 Carson SS, Kress JP, Rodgers JE, et al. A randomized trial of intermittent lorazepam versus propofol with daily interruption in mechanically ventilated patients. Crit Care Med 2006;34(5): 1326-1332

14 Kress JP, Gehlbach B, Lacy M, Pliskin N, Pohlman AS, Hall JB. The long-term psychological effects of daily sedative interruption on critically ill patients. Am J Respir Crit Care Med 2003;168(12): 1457-1461

15 Barr J, Fraser GL, Puntillo K, et al; American College of Critical Care Medicine. Clinical practice guidelines for the management of pain, agitation, and delirium in adult patients in the intensive care unit. Crit Care Med 2013;41(1):263-306

16 Klein Klouwenberg PM, Zaal IJ, Spitoni C, et al. The attributable mortality of delirium in critically ill patients: prospective cohort study. BMJ 2014;349:g6652

17 Jackson JC, Pandharipande PP, Girard TD, et al; Bringing to light the Risk Factors And Incidence of Neuropsychological dysfunction in ICU survivors (BRAIN-ICU) study investigators. Depression, posttraumatic stress disorder, and functional disability in survivors of critical illness in the BRAIN-ICU study: a longitudinal cohort study. Lancet Respir Med 2014;2(5):369-379

18 Svenningsen $\mathrm{H}$. Associations between sedation, delirium and posttraumatic stress disorder and their impact on quality of life and memories following discharge from an intensive care unit. Dan Med J 2013;60(4):B4630

19 Patel SB, Poston JT, Pohlman A, Hall JB, Kress JP. Rapidly reversible, sedation-related delirium versus persistent delirium in the intensive care unit. Am J Respir Crit Care Med 2014;189(6):658-665

20 Schieveld JN, Janssen NJ. Delirium in the pediatric patient: On the growing awareness of its clinical interdisciplinary importance. JAMA Pediatr 2014;168(7):595-596

21 Smeets IA, Tan EY, Vossen HG, et al. Prolonged stay at the paediatric intensive care unit associated with paediatric delirium. Eur Child Adolesc Psychiatry 2010;19(4):389-393

22 Colville G, Kerry S, Pierce C. Children's factual and delusional memories of intensive care. Am J Respir Crit Care Med 2008; 177(9):976-982

23 Jones C, Griffiths RD, Humphris G, Skirrow PM. Memory, delusions, and the development of acute posttraumatic stress disorderrelated symptoms after intensive care. Crit Care Med 2001; 29(3):573-580

24 Magarey JM, McCutcheon HH. 'Fishing with the dead'-recall of memories from the ICU. Intensive Crit Care Nurs 2005;21(6): 344-354

25 Schieveld JN, Leroy PL, van Os J, Nicolai J, Vos GD, Leentjens AF. Pediatric delirium in critical illness: phenomenology, clinical correlates and treatment response in 40 cases in the pediatric intensive care unit. Intensive Care Med 2007;33(6):1033-1040

26 Smith HA, Brink E, Fuchs DC, Ely EW, Pandharipande PP. Pediatric delirium: monitoring and management in the pediatric intensive care unit. Pediatr Clin North Am 2013;60(3):741-760 
27 Smith HA, Boyd J, Fuchs DC, et al. Diagnosing delirium in critically ill children: validity and reliability of the Pediatric Confusion Assessment Method for the intensive care unit. Crit Care Med 2011;39(1):150-157

28 Janssen NJ, Tan EY, Staal M, et al. On the utility of diagnostic instruments for pediatric delirium in critical illness: an evaluation of the Pediatric Anesthesia Emergence Delirium Scale, the Delirium Rating Scale 88, and the Delirium Rating Scale-Revised R-98. Intensive Care Med 2011;37(8):1331-1337

29 Schieveld JN, van der Valk JA, Smeets I, et al. Diagnostic considerations regarding pediatric delirium: a review and a proposal for an algorithm for pediatric intensive care units. Intensive Care Med 2009;35(11):1843-1849

30 Schieveld JN, Staal M, Voogd L, Fincken J, Vos G, van Os J. Refractory agitation as a marker for pediatric delirium in very young infants at a pediatric intensive care unit. Intensive Care Med 2010;36(11): 1982-1983

31 van Dijk M, Knoester H, van Beusekom BS, Ista E. Screening pediatric delirium with an adapted version of the Sophia Observation withdrawal Symptoms scale (SOS). Intensive Care Med 2012;38(3):531-532

32 Traube C, Silver G, Kearney J, et al. Cornell Assessment of Pediatric Delirium: a valid, rapid, observational tool for screening delirium in the PICU. Crit Care Med 2014;42(3):656-663

33 Silver GH, Kearney JA, Kutko MC, Bartell AS. Infant delirium in pediatric critical care settings. Am J Psychiatry 2010;167(10): $1172-1177$

34 Inouye SK, Westendorp RG, Saczynski JS. Delirium in elderly people. Lancet 2014;383(9920):911-922

35 Vos GD, van Os J, Leroy PL, Schieveld JN. Pets or meds: how to tackle misery in a paediatric intensive care unit. Intensive Care Med 2007;33(8):1492-1493

36 Jones C, Griffiths RD, Humphris G. A case of Capgras delusion following critical illness. Intensive Care Med 1999;25(10):1183-1184

37 Playfor S, Thomas D, Choonara I. Recollection of children following intensive care. Arch Dis Child 2000;83(5):445-448

38 Colville G, Pierce C. Paediatric intensive care. The Psychologist 2012;25(3):206-209

39 Colville G, Darkins J, Hesketh J, Bennett V, Alcock J, Noyes J. The impact on parents of a child's admission to intensive care: integration of qualitative findings from a cross-sectional study. Intensive Crit Care Nurs 2009;25(2):72-79

40 Colville G, Pierce C. Patterns of post-traumatic stress symptoms in families after paediatric intensive care. Intensive Care Med 2012; 38(9):1523-1531
41 Tyc VL, Fairclough D, Fletcher B, Leigh L, Mulhern RK. Children's distress during magnetic resonance imaging procedures. Child Health Care 1995;24(1):5-19

42 Upton P, Lawford J, Eiser C. Parent-child agreement across child health-related quality of life instruments: a review of the literature. Qual Life Res 2008;17(6):895-913

43 Kassam-Adams N, García-España JF, Miller VA, Winston F. Parentchild agreement regarding children's acute stress: the role of parent acute stress reactions. J Am Acad Child Adolesc Psychiatry 2006;45(12):1485-1493

44 Noyes J. 'Ventilator-dependent' children who spend prolonged periods of time in intensive care units when they no longer have a medical need or want to be there. J Clin Nurs 2000; 9:774-783

45 Gemke RJ, Bonsel GJ, van Vught AJ. Long-term survival and state of health after paediatric intensive care. Arch Dis Child 1995;73(3): 196-201

46 Atkins E, Colville G, John M. A 'biopsychosocial' model for recovery: a grounded theory study of families' journeys after a Paediatric Intensive Care Admission. Intensive Crit Care Nurs 2012;28(3): 133-140

47 Schieveld JN, Brouwers AG, Schieveld BR. On the lack of standardized essential PICU guidelines. Crit Care Med 2014;42(7): 1724-1725

48 Pandharipande PP, Girard TD, Jackson JC, et al; BRAIN-ICU Study Investigators. Long-term cognitive impairment after critical illness. N Engl J Med 2013;369(14):1306-1316

49 Bronner MB, Knoester H, Sol JJ, Bos AP, Heymans HS, Grootenhuis MA. An explorative study on quality of life and psychological and cognitive function in pediatric survivors of septic shock. Pediatr Crit Care Med 2009;10(6): 636-642

50 Elison S, Shears D, Nadel S, Sahakian B, Garralda ME. Neuropsychological function in children following admission to paediatric intensive care: a pilot investigation. Intensive Care Med 2008; 34(7):1289-1293

51 Colville GA, Pierce CM. Children's self-reported quality of life after intensive care treatment. Pediatr Crit Care Med 2013;14(2): e85-e92

52 Rennick JE, Dougherty G, Chambers C, et al. Children's psychological and behavioral responses following pediatric intensive care unit hospitalization: the caring intensively study. BMC Pediatr 2014;14(1):276

53 Masten AS. Ordinary magic. Resilience processes in development. Am Psychol 2001;56(3):227-238 